\title{
Cannabis policy and the burden of proof: is it now beyond reasonable doubt that cannabis prohibition is not working?
}

\section{SIMON LENTON}

\author{
National Drug Research Institute, Curtin University of Technology, Perth, Western \\ Australia
}

\begin{abstract}
'Innocent until proven guilty' is how many policy makers have thought about the prohibition of cannabis in Western Australia and elsewhere. Comparisons between so called 'decriminalized' and prohibitionist states show decriminalization has not led to higher rates of current cannabis use. Under prohibition significant numbers of Western Australian citizens receive a criminal record for no more serious offence than the possession of a small amount of cannabis for personal use. Recent research has shown that such a conviction can have a real and detrimental impact on people's lives, reinforces disrespect for the cannabis laws, but appears not to deter cannabis use among those so convicted. This paper suggests that it is now beyond reasonable doubt that applying criminal sanctions for minor cannabis offences is not in the best interests of the community and recommends an alternative. [Lenton S. Cannabis policy and the burden of proof: is it now beyond reasonable doubt that cannabis prohibition is not working? Drug Alcohol Rev 2000; 1: 95-100]
\end{abstract}

Key words: cannabis, criminal justice, decriminalization, deterrence, drug policy.

\section{Introduction}

Public calls for drug policy reform often involve calls for implementation of innovative schemes which have been subject to trials or evaluation elsewhere. These are often met by responses from those who oppose such changes that 'more research needs to be done', or 'the data have been short-term', or 'the results are not yet proven'. This contrasts with the way the existing legal framework has been viewed. 'Innocent until proven guilty' is how many policy makers have thought about the prohibition of cannabis in Western Australia and elsewhere. Until recently the application of criminal sanctions to simple possession and use of cannabis has not been the focus of much research or evaluation. This paper examines some of the assump-

Simon Lenton BPsych, MPsych(Clin), Research Fellow, National Drug Research Institute, Curtin University of Technology, GPO Box U1987, Perth 6845, Western Australia. Correspondence to Simon Lenton.

Received 11 April 1999; revised version 11 June 1999; accepted for publication 13 July 1999. 
Table 1. Cannabis use in parts of Australia with different legislation, 1995

\begin{tabular}{lll}
\hline Part of Australia & \% ever tried & \% used last 12 months \\
\hline Where possession and use of cannabis is not a criminal offence & 34 & 12 \\
SA $(n=600)$ & 32 & 12 \\
ACT $(n=500$ & 42 & 16 \\
Where possession and use of cannabis is a criminal offence & 30 & 13 \\
NSW $(n=600)$ & 30 & 13 \\
VIC $(n=600)$ & 31 & 13 \\
QLD $(n=600)$ & 26 & 10 \\
WA $(n=500)$ & 37 & 13 \\
TAS $(n=300)$ & 30 & 21 \\
NT $(n=250)$ & 52 & \\
\hline
\end{tabular}

Adapted from Commonwealth of Australia [3].

tions which underlie beliefs about the effectiveness of our cannabis prohibition, and considers some recent data which bear on these.

\section{General and specific deterrence}

Some politicians and senior bureaucrats often voice the notion that at all costs we need to avoid 'giving the wrong message' when publicly responding to calls for reform of cannabis and other drug laws; the argument being that reducing or removing penalties will in some way condone use and lead to an increased number of users or increased rates of use among those who do use the drug.

\section{General deterrence - 'giving the wrong message'}

When they do this politicians and others are invoking what criminologists refer to as the principle of general deterrence-the prevention of criminal activity by others, in this case the notion that the application of cannabis law is a deterrent to use for those who are not using. This contrasts with specific deterrence-which is the dissuasion of law breakers from further offending, in this case the notion that a cannabis conviction ought deter people so convicted from further use of the drug.

However, research casts doubts on effectiveness of cannabis law as a deterrent to use for those who are not using. The finding of various north American studies from the 1970 s indicated that cannabis laws had a low deterrent effect but produced high social costs[1].
The best measure of the effectiveness of general deterrence is to compare surveys of rates of selfreported cannabis use before and after legal changes have occurred, or across similar locations with different cannabis laws. Single [2] reviewed the effects of the 'decriminalization' of cannabis that occurred in the 11 US states since 1973. Comparisons between socalled 'decriminalized' and prohibitionist states showed that decriminalization had not led to higher rates of current cannabis use in those states.

In Australia, three jurisdictions have introduced expiation notice systems which means that criminal penalties are effectively removed if the fine is paid within a specified period. South Australia (SA) introduced an expiation notice system in 1987, the Australian Capital Territory (ACT) in 1992 and the Northern Territory in 1996. The 1996 The National Drug Strategy Household Survey Report 1995 compared rates of cannabis use in SA and the ACT with that in those Australian jurisdictions which, at that time, had maintained a total prohibition against cannabis use. These figures are presented in Table 1 . The report concluded that the decriminalization of cannabis did not consistently lead to higher rates of use, with SA among the lowest current users, and rates in the ACT behind both the NT and Western Australia (WA) in 1995 [3].

South Australia, being the longest-running example of an expiation notice system in the country, has been evaluated most extensively[4]. A recent analysis of data from the national household survey indicates that over the 10-year period from 1985 there has been an 
Table 2. Adjusted percentage of ever having used cannabis for each jurisdiction 1985-95

\begin{tabular}{lcccccc}
\hline Jurisdiction & 1985 & 1988 & 1991 & 1993 & 1995 & Trend \\
\hline SA & 25.7 & 24.5 & 31.5 & 37.4 & 36.3 & 0.001 \\
TAS & 21.1 & - & 23.6 & 30.2 & 32.9 & 0.001 \\
VIC & 26.4 & 23.1 & 28.2 & 31.2 & 32.0 & 0.001 \\
NSW & 25.6 & 29.7 & 31.5 & 33.0 & 33.0 & 0.01 \\
WA & 31.9 & 34.7 & 36.0 & 36.6 & 37.0 & 0.05 \\
QLD & 26.6 & 24.0 & 27.0 & 30.5 & 29.5 & 0.05 \\
ACT & 35.0 & - & 41.3 & 42.5 & 39.1 & NS \\
NT & 44.1 & - & 47.2 & 49.8 & 52.1 & NS \\
\hline
\end{tabular}

From Donnelly, Hall \& Christie [5].

increase nationally in self-reported lifetime (i.e. ever) cannabis use with a greater degree of increase in SA than in the average of the other Australian states and territories [5]. Between 1985 and 1995, the adjusted prevalence rates of ever having used cannabis increased in SA from $26 \%$ to $36 \%$. There were also significant increases in Victoria (from 26\% to $32 \%$ ), Tasmania (from $21 \%$ to $33 \%$ ) and New South Wales (from $26 \%$ to $33 \%$ ). However, jurisdictions also differed in rates of change, with Victoria and Tasmania having similar rates of increase to South Australia [5]. This is shown in Table 2. It was concluded, therefore, that the South Australian increase in ever having tried cannabis was unlikely to be due to the decriminalization which operates in South Australia[4].

A comparison of recent cannabis use in the various Australian jurisdictions found that there was no statistically significant difference between $\mathrm{SA}$ and the rest of Australia in the rate of increase in weekly cannabis use. The largest increase in weekly cannabis use occurred in Tasmania between 1991 and 1995, where it increased from $2 \%$ to $7 \%$ [5]. These results are presented in Table 3. Taken together, the 'ever use' and 'last 12 months use' data suggest that even if South Australians were slightly more likely to have ever tried cannabis than those in other states, this did not result in higher rates of regular use in that state [4].

In Western Australia, a state with strictly enforced cannabis prohibition, a considerable proportion of the population has not been deterred from using cannabis by the existing criminal penalties [6]. National Household Survey (NHS) data showed that 37\% of West Australians aged 14 or over had tried cannabis, and $16 \%$ had used it in the previous 12 months[2]. Using
Australian population census figures [7] this meant that approximately 500000 West Australians aged 14 years and over had used cannabis at some time, with over 200000 having used the drug in the past year.

Together, this research evidence fails to show that cannabis prohibition has a measurable deterrent effect on the rates of cannabis use in the general population. If removing criminal penalties is 'giving the wrong message' to the general community then it seems that few people are listening.

\section{Specific deterrence - are thase convicted deterred from using?}

As noted above, if cannabis prohibition were to have a specific deterrence effect we would expect that people with a cannabis conviction ought to be deterred from

Table 3. Adjusted percentage of weekly cannabis usage within each jurisdiction 1988-95

\begin{tabular}{lcrrrr}
\hline Jurisdiction & 1988 & 1991 & 1993 & 1995 & $P$ \\
\hline TAS & - & 1.6 & 5.3 & 6.8 & 0.02 \\
WA & 8.0 & 6.5 & 4.7 & 8.9 & NS \\
SA & 2.9 & 7.0 & 6.5 & 4.9 & NS \\
ACT & - & 3.7 & 6.2 & 3.2 & NS \\
QLD & 2.5 & 3.6 & 3.4 & 4.1 & NS \\
NT & - & 10.4 & 9.0 & 10.5 & NS \\
NSW & 4.3 & 4.5 & 3.7 & 4.3 & NS \\
VIC & 3.7 & 3.1 & 3.5 & 3.5 & NS \\
& & & & & \\
\hline
\end{tabular}

Adapted from Donnelly, Hall \& Christie [5]. 
further use of the drug. In testing this hypothesis Erickson [8], in her study of people appearing in court for minor cannabis offences in Canada in the 1970s, asked 95 respondents immediately after their appearance in court about their intention to use cannabis in the next 12 months. She found 53\% said it was 'very likely' and $32 \%$ said it was 'quite likely' that they would use, and that intention to use was strongly related to frequency of use in the year before the court appearance. At 1 year follow-up, intention to use was found to be a good predictor of actual use and specific deterrent effects were found to be similar to those at first interview. Although $8 \%$ reported no cannabis use in the past year, and $8 \%$ used it once a month or less, for the balance of the sample relatively moderate or high levels of use persisted. The few respondents who had ceased to use tended to be those who prior to their conviction were the most infrequent users. Erickson also found that the specific deterrence effects of a cannabis conviction remained low at least up to 1 year after conviction. Furthermore, contrary to the hypothesis that the more severe and certain the punishment the greater the deterrent effect, she found that the more severe sanction was related (although not significantly) with the highest likelihood of ongoing use, and the greater perceived risk of re-arrest was exhibited by those who were most determined to continue use.

Specific deterrence effects were also investigated as part of research into the social impact of the laws that apply to cannabis in South Australia. Sixty-eight West Australians who had received their first criminal conviction as a result of a simple (minor) cannabis offence were asked about their use of the drug in the 6 months before their arrest and the 6 months after their conviction [9]. There were no significant differences between the rates of cannabis use between these two periods. The vast majority (87\%) of the sample said the arrest and conviction had not resulted in them reducing their use of cannabis. Most continued to use despite their conviction because they enjoyed it (62\%), did not see it as a criminal activity $(41 \%)$, saw it as a victimless crime (25\%) or disagreed with the cannabis laws $(22 \%)[9]$.

\section{Why does the law not deter use?}

\section{Lowe levels of social support for cannabis prohibition}

A number of authors have criticised the deterrence perspective for its over-dependence on legal sanctions and have pointed to a range of social factors which may affect adherence to the law [8]. In particular, deterrence effects are undermined where punishments are generally perceived as disproportionate to the crimes and there are low levels of social support for the specific law[10]. In 1993 a telephone survey was conducted of 400 members of the WA public regarding attitudes to cannabis laws and other drug policy issues[11]. The randomly selected sample was representative of the general public in terms of gender and political affiliation at the last election. Consistent with a sampling strategy based on telephone connections, those under 20 and over 60 years of age were under-represented in the sample, so the data were weighted to control for this possible bias. The authors found that $72 \%$ of the sample believed that penalties for personal use should be like those for speeding in a motor vehicle, they should get a fine but not a criminal record'. Sixty-three percent believed that many people in the community use cannabis without experiencing serious problems due to its use, and 63\% also believed that the court system was overburdened with minor cannabis offences. Only $37 \%$ of respondents supported making cannabis 'as legal as alcohol' and $50.7 \%$ believed it would not be a bad thing if 'people were legally able to grow a small amount of cannabis for their personal use' [11].

An analysis of police, court and justice system data for all cannabis offences in WA further supported the lack of public support for the laws that applied to minor cannabis offences. In $199390 \%$ of cannabis charges were for minor offences whereas only $6.0 \%$ were for 'dealing'. In $199298 \%$ of those people appearing before the lower courts with cannabis possession/use as their most serious offence were found guilty and received a criminal conviction. In $1993,42 \%$ (860) of the 2038 people charged with cannabis possession/use as their most serious offence had never been arrested for any prior offence. That is, in that year, two to three Western Australians per day acquired a criminal record as a direct result of a charge for possession of a small amount of cannabis for personal use [6].

The lack of social support for cannabis laws was also found among those 68 respondents in the study of the social impacts of a cannabis conviction in WA [9]. Although $81 \%$ believed that most laws are worth obeying and $85 \%$ believed that police deserve respect for maintaining law and order, $90 \%$ believed that cannabis use should be legal, and $84 \%$ did not believe that strong drug laws deter illicit drug use. Most 
(78\%) of the sample regarded cannabis as a safe drug, and saw it as less harmful than alcohol $(87 \%)$ and tobacco $(69 \%)$. This research has also shown that such a conviction can have a real and detrimental impact on people's lives. Up to 10 years after their conviction $32 \%$ of the sample had at least one negative employment consequence (19\% did not get a job applied for; $16 \%$ lost a job, $9 \%$ stopped applying) as a result of their cannabis conviction. A third (32\%) had further involvement with the criminal justice system (e.g., further police enquiries) as a result of their cannabis conviction. One in five $(20 \%)$ respondents identified at least one negative relationship event, and $16 \%$ identified at least one negative impact on their accommodation which they believed was related to their cannabis conviction. Seven percent identified at least one negative impact of their cannabis conviction on their capacity to travel overseas [9].

\section{Poor certainty of arrest}

The poor certainty of punishment for cannabis offences also serves to undermine any deterrent effects [1]. Additionally it has been shown that the experience of arrest and conviction can lower the perceived risk of legal sanctions produced by committing criminal acts[12].

Looking at the WA situation, it has been estimated that based on NHS figures approximately 200000 West Australians will use cannabis in any one year and that their will be about 2500 people whose most serious offence will be a minor cannabis offence [6]. This means that in any one year, the likelihood of any user being convicted as a direct result of a minor cannabis offence is approximately $1.25 \%$. Given the number of episodes of use by the average cannabis user in any one year, the risk of conviction on any one using episode must be less than 0.01 of $1 \%$; so the chances of being convicted are indeed small.

\section{Conclusion}

This paper has aimed to show that the application of criminal sanctions to minor cannabis offences has both failed to deter cannabis use in the general community and failed to deter subsequent cannabis use among those convicted. Reasons for its failure include low levels of support for cannabis prohibition in the general community, a public perception (supported by the evidence) that the application of a criminal penalty can have a serious and long-lasting detrimental impact, and finally the low certainty of arrest for cannabis use. In conclusion I would argue that it is now beyond reasonable doubt that applying criminal sanctions for minor cannabis offences does not deter cannabis use but results in significant social costs for those who run foul of it, and therefore that it is not in the best interests of the community.

The question then becomes; what legislative model is most appropriate for cannabis? Although a thorough answer to this question is not possible here, six possibilities have been described elsewhere [13]. These include total prohibition without an expediency principle, total prohibition with an expediency principle, prohibition with civil penalties for minor offences (expiation notice schemes), partial prohibition, regulation and free availability. Free availability and regulated supply, other than for medical treatment, are ruled out through Australia's international treaty obligations. It is likely that making possession and use of small amounts of cannabis legal while maintaining criminal sanctions for possession of larger amounts and supply offences (partial prohibition) would also contravene these international conventions. The prohibition with civil penalties option, such as the infringement notice schemes which already operate in three Australian jurisdictions, has been shown to have wide community support, not to have been prevented by the international treaties, and can result in significant reduction in social impact for those apprehended while not being significantly worse than the total prohibition approach in deterring cannabis use. The next task is to use the research evidence to fine-tune existing examples of infringement notice schemes, and design, trial and evaluate new ones, to maximize the benefits and minimize the harms of this approach to managing cannabis use in the community.

\section{Acknowledgements}

This paper is based on a presentation made at the 13th Mandurah Addiction Symposium, Mandurah, Western Australia, 7-8 October 1998.

\section{References}

[1] Erickson P. The law, social control, and drug policy: models, factors and processes. Int $\mathrm{J}$ Addict $1993 ; 28: 1155-76$.

[2] Single EW. The impact of marijuana decriminalisation: an update. J Public Health Policy 1989;10: $456-66$. 
[3] Commonwealth of Australia National Drug Strategy. Household Survey-Survey Report 1995. Canberra: Australian Government Publishing Service, 1996.

[4] Ali R, Christie P, Lenton S, Hawks D, Sutton A, Hall W, Allsop S. The social impacts of the cannabis expiation notice scheme in South Australia: survey report. Canberra: Australian Government Publishing Service, Commonwealth Department of Health and Aged Care, National Drug Strategy, 1999.

[5] Donnelly N, Hall W, Christie P. Effects of the Cannabis Expiation Notice scheme on levels and patterns of cannabis use in South Australia: evidence from the National Drug Household Surveys, 1985-1995. Canberra: Australian Government Publishing Service, Commonwealth Department of Health and Aged Care, National Drug Strategy, 1999.

[6] Lenton S, Ferrante A, Loh N. Dope busts in the West: minor cannabis offences in the Western Australian criminal justice system. Drug Alcohol Rev 1996;15:335-41.

[7] Australian Bureau of Statistics. Estimated resident population by sex and age states and territories of Australia June 1994 and preliminary June 1995. Canberra: Australian Government Publishing Service, 1996.
[8] Erickson P. Cannabis criminals: the social effects of punishment on drug users. Toronto: Addiction Research Foundation, 1980.

[9] Lenton S, Bennett $M$, Heale $P$. The social impact of a minor cannabis offence under strict prohibition - the case of Western Australia. Perth: National Centre for Research into the Prevention of Drug Abuse, Curtin University of Technology, 1999.

[10] Bierne P. Inventing criminology: 'the science of man' in Beccaria's Dei delitti e delle pene. In: Henry $\mathrm{S}$, Einstadter W, eds. The criminology theory reader. New York: New York University Press, 1998.

[11] Lenton S, Ovenden C. Community attitudes to cannabis use in Western Australia. J Drug Issues $1996 ; 26: 783-804$.

[12] Apospori E, Alpert GP, Paternoster R. The effect of involvement with the criminal justice system: a neglected dimension of the relationship between experience and perceptions. Justice Q 1992;9:379-392.

[13] McDonald D, Moore R, Norberry J, Wardlaw G, Ballenden $\mathrm{N}$. Legislative Options for Cannabis in Australia. National Drug Strategy Monograph No. 26, Canberra: Australian Government Publishing Service, 1994. 